\title{
Women Language Features in Recode World's Technology Conference: A Sociolinguistic Studies
}

\author{
Deby Rahmawati ${ }^{1)}$, Elvi Citraresmana ${ }^{2)}$, Lia Maulia Indrayani ${ }^{3)}$ \\ ${ }^{123}$ Universitas Padjadjaran \\ Email:rahmawatideby30@gmail.com \\ ${ }^{2}$ Universitas Padjadjaran \\ Email:elvi.citraresmana@unpad.ac.id \\ ${ }^{3}$ Universitas Padjadjaran \\ lia.maulia.i@gmail.com
}

\begin{abstract}
This research analyzes the women language features in giving public speeches in RECODE World's Technology Conferences. The writer used Lakoff's on Holmes (2013) theory to analyze the data. The writer applies descriptive qualitative method by Creswell (2014). Data for this reseach is women utterance during conference. Basen on theory by Lakoff, the author discover six women language features.The result of this research shown that there are six women language feature that appear, there are lexical hedges, intensifier, superpolite form, avoidance strong swear, empty adjective, and emphatic stress.
\end{abstract}

Keywords: sociolinguistics, gender language, women language features

\section{INTRODUCTION}

In conducting an interaction, of course we need participants, that is, there is a speaker and listener. Speech is a process of talking to a group of people in a form to inform something, influence, and even entertain the listeners. At a conference or in any form of communication, there is a basic question that is often asked which is "who, what to whom, what medium with what effect?" The purpose of the conversation between the speaker and the listener can range from simply sending information, motivating people to action, and also just telling a story of the speaker's life journey. A good speaker must of course be able to change the emotions of their listeners, not only to tell them, but the speaker can change the listener's view of incorrect information public speeches or conferences can also be considered community discourse. Speeches or conferences contain elements of discourse community that exist in many media and forms that serve different purposes for society and business among other fields of communication. Public speech has several components that include things like motivational speaking, leadership or personal development, business, customer service, large group communication, and mass communication. a conference or public speech can be a very powerful tool to be used for purposes such as motivation, influence, persuasion, informing, translating, or simply entertaining the listener. 
The study of communication between genders has been an interesting topic in this modern era. One of the important issues between man and women is the way they are use their own language for communication style to interact to each other. In general, one well-known gender difference in communications is that man are direct how they communicate, they are also more authoritative and forceful, while women are more polite, more gentle and more emotional. Different kinds or style of communicative competence can occur and human use their communicative strategies for various reason. That is why variant in communicative style may lead to miscommunication.

The issue of gender differences has been around for a long time, for example regarding material facts, differences, nonphysical, or can be said to challenge or break down as gender. Every individual is created by various aspects, for example society, historical or cultural background and so on. Gender differences between men and women in society certainly have different roles. Women are seen as passive or feminine and men are considered as active or masculine. According to Haeberle's theory (1981: 9) explains the social role of men who are designed to support as a masculine male figure, while the social role of women is to offer to be a feminine woman. Because of such stigma, many men assume responsibility for finding work, working and achieving their achievements. Whereas women must carry out their household responsibilities or be made one step below asking the man he can. The division of rules is called the role of traditional gender which is still common in all countries.

Both women and men who live in the same environment have different relationships with the community as if each has a different environment and culture. The difference between men and women is reflected in the language they use. Even though women and community members speak the same, they can use different forms of linguistics according to the context of the conversation. The forms of linguistics used by both women and men certainly have differences with several factors, especially factors of educational background, work, the context of the speech situation and so forth.

Based on Lakoff (1975), in a conversation or discussion, the way women and men in delivering the contents of the conversation have differences; it reflects their social status in society. This happens because women are considered to have no power in society, so the opinions of women are often considered irrelevant due to the powerless figure of women. He also stressed that women generally lack status in society. Therefore, it is said that women are inferior to men. Men are more aware of the fact that their social status can be seen from the way they speak. Women are indicated to hedge and enhance their speech to attract the attention of the listener. In addition to hedging and enhancing, women as guardians of community values are also expected to be polite and must speak in a standard form. Conversely, men are generally more tolerant, more free, rude and naughty than women in having a conversation.

This research area is discussing the relationship between language and gender. Many studies discuss how men who are considered less polite when having a conversation than women who are considered more polite. Research on gender language and politeness showed that men tend to be less polite because they 
use direct strategies without paying attention to faces, especially less positively polite than women. In this study, there was a significant difference in politeness depending on the sex of the conference participants.

In this research, the writer use data from RECODE World's Technology Conference, the writer will describe how language features of women speakers during conference. The writer choose the data because the data presented several influential people in the field of technology. The writer wants to prove whether the Lakoff hypothesis applies to certain situations such as at a conference attended by influential people who certainly have educational backgrounds, career backgrounds and etc.

Based on explanation above, the writer interested in conducting further research on the language features of women and men and politeness strategies entitled "Women Language Features in RECODE World's Technology

Conference". The writer will analyze and describe from the question about what are the types of women language feature in RECODE World's Technology Conference.

\section{Sociolinguistic}

Sociolinguistic is a study about social structure of community, and then linguistics is a study about language in society, next pragmatics is kind about meaning and the context. Holmes (2001:1) "Sociolinguistics is to study the relationship between language and society". Sociolinguistics concerns with the relation between the language and also the context in which it is used. In short it can be concluded that sociolinguistics study is related to communities as well as social factors about societies and their utterances.

Sociopragmatic can be considered saying the same thing in different ways. The speaker concern to whom they speak thus they use different ways of speaking. The speaker may use different vocabulary to different hearers with different class, several variations for the speakers to speak the language they use. The speaker and the hearer, however still understand each other although the speaker uses variations of speaking language itself and also dialect.

\section{Women's Speech Feature}

Based on Lakoff (1975), she describes women's language in terms of disabilities resulting from women's political and cultural subordination produced by men. In his perspective, the linguistic features of women's language describe them as individuals who are tentative, uncertain and lacking authority and are subject to anything. Lakoff (1975) divided women's speech feature into ten types as mention below.

\section{Lexical Hedges or Fillers}

One feature women talking proposed by Lakoff (2004: 79) is a lexical hedge. Basically, hedging function is to indicate doubt or confidence in what has been said. Some examples of hedging in women's language are like kind words, you know, somewhat, like, you know, somewhat / sort of, like, I think, I guess and it seems. See the example below:

a. I guess the advisor will come this afternoon

b. Farrell is sorta tall

By looking at these examples, it can be seen that sentence a shows that the speaker feels uncertain and lacks confidence in expressing his intention or content. The 
speaker did not know exactly whether the adviser was really coming in the afternoon or not so he used the word "I think" to protect his statement. Then, what is meant by the speaker in sentence $b$ is that Farrell doesn't look too tall or too short. In the case of sentence $b$, hedging can be used to reduce the likelihood of being unfriendly or unfavorable to the speaker's statement which is uncomfortable to tell about one's physical weakness. For the sake of courtesy to the listener, hedges are used by the speaker to blunt the power of statements that are rather painful.

\section{Tag Questions}

The other women "s speech feature proposed by Lakoff is tag question. Tag question is midway between an outright statement and a yes-no question. It is less assertive than the former one, but more confident than the latter (Lakoff, 2004:48). Tag question is a kind of polite statement that does not force the agreement or belief on the addressee. In the following, Lakoff's theory of tag questions was developed by Holmes (1992: 318) where he said that tags are not always used to express uncertainty but can function as facilitative tools. Question tags are usually used by teachers, interviewers or those who have a leadership role as their facilitative way to succeed their interactions. In addition, it can also be used to refine direction or criticism.

For examples:

a. Farrell is here, isn't he?

b. Are you waiting for your friend, aren't you?

These examples above can be seen that both sentence $a$ and $b$ show for having more confident than latter. In sentence $a$, the speaker believes that Farrell really is in the place that the speaker means. Then, in sentence $b$ have convinced on the addressee.

\section{Rising Intonation on Declarative}

This feature is found in a form of declarative sentence used to answer question but typically has a rising intonation similar to yes-no question intonation. As stated by Lakoff (2004:50), the use of rising intonation indicates that there is unwillingness to be very assertive in carrying an opinion. Through this feature, the speaker provides a confirmation since she is unsure if her opinion will be agreed by the addressee so that rising intonation in declaratives is used to show that the speaker leaves the decision open to the addressee in a nonforceful way.

\section{Example:}

Oh... it has already six o'clock?

Question intonation found in the sentence above is example of declarative sentence that has a rising intonation which is usually used by someone who wants deliver a question. The example above means that the speaker gives the addressee the chance to negotiate the decision and find the agreement.

\section{Empty Adjective}

The presence of empty adjectives in women's language indicates that the speaker wants to show the emotional connection between the speaker and the listener. In addition, it is also used to indicate approval or admiration speaker on something (Lakoff, 2004:25). Some of these adjectives are neutral in which both men and women can use them while some of these adjectives are largely used more 
by women. The representatives of both types are as follows:

$\begin{array}{ll}\text { Neutral } & \text { Women Only } \\ \text { Great } & \text { Adorable } \\ \text { Terrific } & \text { Charming } \\ \text { Cool } & \text { Sweet } \\ \text { Neat } & \text { Lovely } \\ & \text { Divine }\end{array}$

Women can freely use neutral adjectives, while men are more at risk of using female adjectives because it can damage their reputation or can embarrass a man who is considered masculine. Through the way women have their choice of words; they want to show something different about their personality or opinions about the problem.

Look at this example:

a. What a great idea!

$b$. What a divine idea!

From the examples given, women can use sentence a under the appropriate conditions while sentence $b$ is more limited and can be used correctly when feeling that the idea referred is seen as something that is not important and is only an entertainment for female speakers (Lakoff, 2004: 46). In short, women are free to use both words

\section{Precise Color Term}

The function of the precise color term is to name or mention a color. A woman has the ability to interpret colors differently from men. Women have the ability to mention color terms more clearly than men, such as maroon, beige, ecru, lavender or aqumarine. Vocabularies about these colors are often well identified by women. Meanwhile, men generally do not care about the accuracy in naming colors and what women do because they do not involve their emotions, in contrast to women who always question the accuracy of color (Lakoff, 2004:43). Arguing whether a particular color is mauve or lavender for men is seen only as a trivial matter.

\section{Intensifier}

Other features found in conversations or conferences on women are reinforcement such as so, fair, very, very, or very. According to Lakoff's theory (2004: 48), using an intensifier is a way to back down from a commitment to an opinion, more like a tag question. If women use hedges to express uncertainty about their own opinions, the use of amplifiers in women's conversations is to persuade their recipients to take them seriously and to reinforce the meaning of their utterances.

According to the theory of Holmes (1992: 316) suggests that the intensifier as a reinforcement tool reflects the anticipation of the speaker that the listener can remain unsure so she uses the intensifier word to supply additional guarantees. Women usually increase the strength of their speech because they think that if not they will not be heard or noticed by the listener. Look at the example below:

a. We feel really enjoy!

b. Your performance is so beautiful!

When we look at the examples above, in sentence $a$, using the word "really" as the function for strengthen the meaning of the enjoyable. It means that in the utterance has extra enjoy in their feeling. Then, in sentence $b$, the word "so" helped the utterance to making convince which she really nuts about the performance. 


\section{Hypercorrect Grammar}

In conducting a conversation, a woman must be polite and not speak rudely to the listener. One example given by Lakoff (2004: 80) is the use of $g$ 'in the word singin' which is more dropped by men than women do. Holmes (1992: 167) suggests that in every social class, women tend to use standard or more grammatical forms of conversation than men, meanwhile, in conducting conversations men use more forms of language than women. Holmes said that women use more pronunciation than men.

Not only Lakof's theory, but also various reasons put forward by Holmes (1992: 171) which explains why women use the standard form of conversation more than men. This is because women generally do not have status in society. In this way, the standard form of speech spoken by women is associated with high social status so that women use more standard speech as a way of claiming that status.

\section{Superpolite Form}

The next feature of female language is a very polite form. This relates to the fact that women should behave and communicate politely and very carefully. Women use super polite form in their conversation in several ways, for example, is the less assertive words, make requests indirectly, euphemism and grammar hypercorrect.Women's speech differs from men's in that women are more polite, which is precisely as it should be since women are the preservers of morality and civility, (Lakoff, 2004:77)

Examples:

a. Would you please turn on the lamp, if you don't mind?

b. Could you give me the example?
The examples above show that women try to be polite by making their request indirectly, which is delivered in a form of question. Through this way, they leave the decision to receive the request depend on the addressee without an attempt to impose what they want or appear in their mind. The more particles in a sentence that reinforce the notion, that it is a request rather than an order, the politer the result (Lakoff, 2004: 50).

\section{Avoidance of Strong Swear Word}

Swearing is kinds of interjection that can express extreme intensify. It has been widely considered as an expression of very strong emotion. Women usually use softer forms such us 'Oh, Dear!' or 'Darn!' while the men use stronger ones such as 'Dammit!' or 'Shit!', (Rafi', 2014:19)

Lakoff (2014: 44) states that as a child, a woman is encouraged to become a 'little girl'. as a little girl don't scream as loud as a boy, get punished more loudly for making anger or showing anger. See the example below: A. Oh baby, you broke my glasses B. Damn, you broke my glasses

From the example above, we can see the difference between sentence a and sentence $b$. We can classify sentence a as part of 'female language', then $b$ as' male language.

\section{Empathic Stress}

The last feature is empathic stress, known as speaking slant. This refers to how to express uncertainty with our own expression. The speaker uses tones to emphasize certain words such as fabulous, very, very, very, or enough. According to the theory of Lakoff (2004: 81) defines that spoke with emphatic stress is a form 
of referrals to tell someone how to react because of what was said by the speaker is less convincing that it is better to use double the power to ensure that the listener can understand what is being said by the speaker. Examples:

a. It is great performance!

b. Did you know my score? Really?

Great words in a sentence and the sentence actually $b$ are some examples of emphatic stress. These words can be used to reinforce the meaning of words.

\section{METHOD}

This part of the method is closely related to how the research was conducted by the author and managed so that the research objectives are achieved. In this section there are some sections that discuss how research is conducted and managed so that the research objectives achieved. The writer applies descriptive qualitative method which means the description or the condition of such phenomena will be the issue that the writer concern about. Qualitative research explores question such as what, why and how, rather than how many and how much, it is primarily concerned with meaning rather that measuring (Keegan, 2009: 11). There are three types of qualitative research method. Those are collecting the data, analysis and interpretation that researchers propose for their studies (Cresswell, 2014: 45). In analyzing the data, the writer performs step by step. First, the writer downloads the video of the speech. Second, create the transcript from video format into Microsoft Word. Third, change the format of data from Microsoft Word into excel format for classification.
The Method and Technique of Data Collecting

After all of data are collected, the next step is data analysis where the utterances are explained as in the following steps:

\section{The Method and Study Techniques}

Regarding the method of study technique in this research, the writer identified the data into two ways of classification. First is classifying the data based on the language features of women and men theory as a sociolinguistics study, then classifying them based on the context and politeness strategies as a pragmatics study. Here, the writer uses several steps, as follow:

1. Having the transcript of RECODE World's Technology Conference, the writer scanned the scripts so carefully to find language features of women and men.

2. Focusing the analysis on the language features of women from the transcript by figuring out women or men utterances during conferences.

3. Concluding the data analysis based on the method of study technique above.

\section{Source of Data}

Data of the research are all of the women utterances that is expert in technology. The author takes four speeches because those speeches have represented for this research. The data is gotten from official website RECODE in January 2019. RECODE World's Technology Conference is technology news website that focuses on the business of Silicon Valley. In this research, the writer choose data from Hillary Clinton, and Emily Steel as New York Times reporter. This research 
focused on women language features used by Hillary Clinton and Emily Steel as New York Times reporter in their conferences to describe their personality in speech. Meanwhile, the data is words, phrases, clauses which contain by women language features on RECODE World's Technology Conferences which reflect some types of gender language features proposed by Lakoff (1975).

\section{FINDINGS AND DISCUSSION}

\subsection{Lexical Hedges}

Swisher : Now let's just get the all right platform - Hillary Clinton has a drinking problem [HRC laughs]. But if you'd like a drink at any point, this is for you to take home.

Hillary : Well, you know, it may depend upon how the interview goes.

Based on the data found in this study, among other features found in utterances of the RECODE technological conference, lexical hedges is one of feature that most often appears in women's utterances. Based on Lakoff, Lexical hedges express women's confidence during conversation. Lexical hedges like well, I guess, kind, kind of, like and you see, sort of lack of confidence in women nowadays. That features are used by women who are not sure of something. While fillers like uhh and umm are features that help women to pause to support what they want to say. Based on Lakoff, the lexical hedges is an insignificant particle that provides a respite for women to understand what they want to say. In this data, Hillary needed a little time to ask what she would to say in her words because she had prepared it. Hillary looks very insecure and uncomfortable because of the conversation where she has to give a speech in front of so many people at a technology conference. Based on Cameron (2005) it shows that women are not comfortable speaking in public because women often hesitate to speak in public because of stereotypes and prejudices about how they speak and write. The purpose of Hillary's use is to start the topic of discussion that drinks alcohol and also the words you know to drink anytime and that depends on the way the interview goes, it shows she is not sure the compilation states it. Hedging hedges also and you know used by Hillary to compile him to start the discussion and he also involves implicitly asking the other person to know what he wants and what to talk about. Hillary used lexical hedging in this case to argue, to start discussions and get responses from Mossberg and Kara Swisher.

\subsection{Empty Adjective}

Mossberg : Yeah, sounds like New York.

Hillary :Right. Right, and it's interesting. We're both pretty ambitious and really persistent reporters, and we take our approach and our strategy to stories a little bit different and I maybe have a softer approach. I have a higherpitched voice and I'm pretty sweet, and he is very, very persistent and much more aggressive. I'm aggressive too, but in a sweet way.

Based on lakoff (1973) women have different views of their choose words. Women used empty adjectives when they are want to express their feeling towards something or someone in a particular situation. There are some words such as cute, charming and etc have trivial meanings that are used to make it sound more amusing. In the utterance, Hillary 
uses this feature once due to her personality. Hillary's personality is someone who tends to act normal like pretty sweet that her opponent. When it comes to expressing her feeling and describing someone, Hillary mostly uses intensifiers with common adjective, but it depends on the person she talks to. In this conversation, Hillary is trying to do something for her hearer. Therefore, Hillary compliments her opponent to reveal her emotional reaction by saying her personality is pretty sweet before she say her opponent is arrogan.

Hillary have an extended vocabulary to express their emotions verbally. However, the word pretty sweet here has trivial meanings. Hillary only uses it because the word contains an amusing meaning and that she wants the audience to be happy while complimenting herself before putting her opponent down. Also, Hillary tend to express what she felt including her opinions to other easily. Hence, Hillary uses this feature in order to express her feeling and her opinion of her opponent.

\subsection{Intensifier}

Mossberg : This is the DNC you're talking about.

Hillary : So raised - best estimates are close to a hundred million dollars, they brought in their main vendors, they basically said, "We will never be behind the Democrats again," and they invested between 2012 and 2016 this hundred million dollars to build this data foundation.

During the conversation, Hillary uses an intensifier on her utterances such as really, very and sorry. She also uses just, so really and very as intensifier to stress, to strengthen her intended meaning and also to make sure that the hearer receive the message. The word so shows that Hillary says it emotionally and she wants the hearer take the message seriously. In this sentence, Hillary uses intensifiers tend to focus attention toward the emotional message and away from the cognitive meaning of the statement. Based on the conversation during the conference, women says so a couple times. This phenomenon is match with fact of gender from Tannen (1990) reveal that women often talk too much rather than men. Both Hillary or Emiliy uses the word so repeatedly even tough her main point is only to emphasize to the presenter and the audience. This shows that women talks too much because based on Tannen (1990) argues that for most women it is basically a way of establishing connections and negotiating relationships between the speaker and the listener.While Hillary or Emily saying so both of them also expresses their feelings to the presenter or audience to emphasize her argument or compliment. Both Hillary and Emily express their feelings or opinions to get attention from the hearer.

\subsection{Superpolite Form}

Hillary

[laughter].

Mossberg

from Kara.

Hillary

: Thank you, Kara, thank you

: That's actually a kind thing

:I'm very touched!

Superpolite form are usually uased as a polite command and also polite language. Women aften uses this feature for more polite utterances while speaking. By superpolite form for ask a favor to her 
addressee by suggesting something to be done as a favor for themselves. And they want to speak to the interlocutor politely without harming the feeling using this feature. By using superpolite form is also an imperative statement but women use it in a more polite way. Both Hillary and Emily usually uses phrases such as thank you which shows usual polite form.

\subsection{Avoidance Strong Swear}

Hillary : "Oh my gosh, Hillary Clinton is running a child trafficking operation in Washington with John Podesta." Well, you don't believe it, but this has been such an unbelievable election, you kind of go, "Oh maybe I better look into that."

Based on the data above, Hillary use avoidance strong swear word oh my gosh to show how strongly she feel about child trafficking operation in Washington. The word oh my gosh is come from her mouth when she is surprised of something without saying the swear words.

\subsection{Emphatic Stress}

Swisher : What about a financial element? That they made money from this?

Hillary : we had a great tech program. We had a really good set of policies.

The next feature of the discussion on women language feature is emphatic stress. Emphatic stress usually refers to how to express uncertainty with our own expression. In this data Hillary uses tones to emphasize certain words such as great, very, etc. In this section, the entire emphasis on emphatic stress is a form of direction to tell the listener how to react because what the speaker is saying is inconclusive so he or she will be better off using double power to ensure that the listener can understand what the speaker is trying to convey.

\section{CONCLUSION}

From the result of this research, it can be conclude that Sociolinguistic has been applied to oral discourse between speech and also the meaning based on gender. The writer concludes that there are significant difference between women and men language features. The basis for identification varies, namely the question is determined by looking at the linguistic instructions, requests and offers are identified through communicative functions of utterances.

Based on the result of this research it can be conclude that

1. Women are more verbally intelligent than men.

2. Problems that arise from language and communication are more important for women than men because women talk more often than men. The topic discussed can also be out of the context of the conversation.

3. The purpose of women in using the language when communicating is to talk about one's feelings and relationships between people.

4. Women is more cooperative which reflect their preferences for equality and harmony. 


\section{REFERENCES}

Arliss, L. P. (1991. Gender Communication. New Jersey: Prentice Hall.

Cameron, D. (2003). Gender And Language Ideologies. In J. Holmes, \& M. Meyerhoff, The Handbook of Language and Gender (Pp. 447-467). Maiden: Blackwell Publishing Ltd.

Cameron, D. (2005). Language, Gender, And Sexuality: Current Issue and New Directions. Applied Linguistics 26/4: 482-502, 1-21.

Cameron, D. (2003). Language And Sexuality. New York: Cambridge University Press.

Crawford, M. (1995). Talking Difference On Gender and Language. California: SAGE Publications India Pvt Ltd.

Holmes, J. (1992). An Introduction to Sociolinguistic. New York: Longman Group UK Limited.

Holmes, J. (2013). An Introduction to Sociolinguistics. New York: Routledge.
Lakoff, R. (1973). Language and Woman's Place. Language In Society, 45-80.

Mason, J. (2002). Qualitative Researching. Londong: SAGE Publications Ltd.

Stubbs, Michael (2007). Collocations And Semantic Profiles: on the Cause of the Trouble With Quantitative Studies.

Stubbs, Michael (1983). Discourse Analysis: The Sociolinguistic Analysis of Natural Language. University of Chicago Press.

Tannen, D. (1990). You Just Don't Understand Women and Men In Conversation. USA: Ballantine Books.

Wardhaugh, R. (2006). An Introduction to Sociolinguistics Fifth Edition. UK: Blackwell Publishing Ltd.

Wardhaugh, R. (1992). An Introduction To Sociolinguistics Second Edition. Massachussets: Blackwell Publishers. 